https://doi.org/10.1590/198053145980

\title{
O PERFIL DISCENTE DAS UNIVERSIDADES FEDERAIS MUDOU PÓS-LEI DE COTAS?
}

\author{
Adriano Souza Senkevics' \\ Ursula Mattioli Mello"
}

\section{Resumo}

Esta pesquisa objetiva fornecer insumos para o processo de monitoramento e avaliação da Lei de Cotas (Lei n. 12.711/2012), por meio da investigação das alterações no perfil socioeconômico e racial do corpo discente das instituições federais de educação superior (Ifes) de 2012 a 2016. Para tanto, desenvolvemos uma análise exploratória do perfil dos ingressantes dos cursos presenciais de graduação das Ifes com base no cruzamento de dados do Censo da Educação Superior (2012-2016) e do Exame Nacional do Ensino Médio (2011-2015). Nossos resultados sugerem que a Lei de Cotas tem apresentado resultados inclusivos sobre a maioria das Ifes no Brasil (com efeitos contraditórios em algumas), em especial entre os ingressantes provenientes da rede pública e os autodeclarados pretos, pardos e indígenas.

AÇÃO AFIRMATIVA • EDUCAÇÃO SUPERIOR • RELAÇÕES RACIAIS • RESERVA DE VAGAS

\section{HAS THE STUDENT PROFILE OF FEDERAL UNIVERSITIES CHANGED AFTER THE LEI DE COTAS?}

\section{Abstract}

This study aims to provide input for the process of monitoring and evaluating the Lei de Cotas [Quota Law] (Law No. 12.711/2012) by investigating changes in the socioeconomic and racial profiles of the student body of federal higher education institutions (Ifes) from 2012 to 2016. To do so, we developed an exploratory analysis of the profile of incoming students, enrolled in undergraduate courses in Ifes, based on data from the Higher Education Census (2012-2016) and the Exame Nacional do Ensino Médio [National High School Exam] (2011-2015). Our results suggest that the Lei de Cotas has produced inclusive results on most of the Ifes in Brazil (with contradictory effects on some), especially among newcomers from the public network system and the self-declared black, pardo and indigenous peoples.

\section{AFFIRMATIVE ACTION • HIGHER EDUCATION • RACE RELATIONS • RESERVATION OF SQUARES}

\footnotetext{
1 Agradecemos aos pesquisadores Rachel Pereira Rabelo e Alexandre Ramos de Azevedo por nos ajudarem a refletir sobre os caminhos desta pesquisa e à Diretoria de Estudos Educacionais (Dired) do Instituto Nacional de Estudos e Pesquisas Educacionais Anísio Teixeira (Inep) pelo apoio em sua realização. As opiniões emitidas nesta publicação são de exclusiva e inteira responsabilidade dos autores, não exprimindo necessariamente o ponto de vista do Inep ou do Ministério de Educação (MEC).

I Instituto Nacional de Estudos e Pesquisas Educacionais Anísio Teixeira (Inep), Brasília (DF), Brasil; https://orcid.org/0000-0003-2311-1072; adriano.senkevics@inep.gov.br

II Universidad Carlos III de Madrid (UC3M), Madri, Espanha; https://orcid.org/O000-0002-7148-4685; umattio/@eco.uc3m.es.
} 


\section{LE PROFIL DES ÉTUDIANTS DES UNIVERSITÉS FÉDÉRALES A-T-IL CHANGÉ APRĖS LA LEI DE COTAS? \\ Résumé}

Cette recherche vise à contribuer au suivi et au processus d'évaluation de la Lei de Cotas [Loi des Quotas] (Loi no 12.711/2012), par moyen d'une étude sur les changements intervenus dans le profil socioéconomique et racial de la population étudiante des institutions fédérales d'enseignement supérieur (Ifes), entre 2012 et 2016. Nous avons à cette fin réalisé une analyse exploratoire du profil des étudiants accedant au premier cycle, appuyée sur le croisement des données du Recensement de l'Enseignement Supérieur (2012-2016) et de l'ENEM, Exame Nacional do Ensino Médio [Examen National de Conclusion des Études Secondaires] (20112015). Nos résultats indiquent que la Lei de Cotas a favorisé l'inclusion dans la plupart des Ifes au Brésil avec, (malgré des effets contradictoires dans certaines d'entre elles), notamment en ce qui concerne les étudiants issus des établissements publics et les autodénominés noirs, métis et indigènes.

\section{DISCRIMINATION POSITIVE • ENSEIGNEMENT SUPÉRIEUR • RAPPORTS DE RACE • RESERVATION DE CARRÉS}

\section{¿EL PERFIL DISCENTE DE LAS UNIVERSIDADES FEDERALES CAMBIÓ DESPUÉS DE LA LEI DE COTAS?}

\section{Resumen}

Este estudio tiene como objetivo proporcionar insumos para el proceso de monitoreo y evaluación de la Lei de Cotas [Ley de Cuotas] (Ley no 12.711/2012), a través de la investigación de los cambios en el perfil socioeconómico y racial del alumnado de las instituciones federales de educación superior (Ifes) de 2012 a 2016. Para ello, desarrollamos un análisis exploratorio del perfil de los ingresantes de los cursos presenciales de graduación de las Ifes con base en el cruce de datos del Censo de la Educación Superior (2012-2016) y del Exame Nacional do Ensino Médio [Examen Nacional de la Enseñanza Media] (2011-2015). Nuestros resultados sugieren que la Lei de Cotas ha presentado resultados inclusivos sobre la mayoría de las Ifes en Brasil (con efectos contradictorios en algunas), en especial entre los ingresantes provenientes de la red pública y los autodeclarados negros, pardos e indígenas. 
ESDE AS ÚlTIMAS DÉCADAS, TEM SIDO EVIDENTE UM PROCESSO DE EXPANSÃO DAS

vagas e o incremento no número de matrículas de estudantes de graduação no Brasil. Historicamente acessível para os estratos sociais mais privilegiados, as universidades e faculdades pelo país têm se tornado progressivamente mais abertas para camadas sociais que até então pouco usufruíam o direito à educação em nível superior. Tal ampliação de vagas é marcante principalmente a partir de meados da década de 1990, quando se retomou um processo de expansão estagnado por aproximadamente duas décadas (NEVES; RAIZER; FACHINETTO, 2007), e intensificado desde os anos 2000, momento em que a progressiva implantação de políticas inclusivas na esfera privada caminhou em paralelo ao crescimento do setor público, capitaneado pelo Programa de Apoio a Planos de Reestruturação e Expansão das Universidades Federais (Reuni). Em contrapartida, é sabido que o ensino público, ofertado principalmente pelas universidades e institutos federais, é mais escasso se comparado à participação das instituições privadas e, em concordância com Neves e Martins (2016, p. 96), ainda incapaz de "sustentar um processo consistente de inclusão social”.

Em razão da expansão bastante tardia do setor público no contexto internacional, o ensino superior brasileiro é palco de persistentes desigualdades de acesso e conclusão observáveis por uma gama de indicadores sociais (ARTES; RICOLDI, 2015; RIBEIRO; SCHLEGEL, 2015). Com uma taxa líquida de escolarização 
de apenas $21,2 \%$ em 2014, sendo $30,6 \%$ para brancos e $14,0 \%$ para negros (autodeclarados pretos e pardos), e 53,6\% para o quintil de renda mais elevado e somente 4,9\% para o menor quintil de renda (INEP, 2016), são visíveis as disparidades que marcam as dificuldades de acesso e permanência dos jovens brasileiros, particularmente dos negros e oriundos de famílias de baixa renda. Com o intuito de reverter esse quadro histórico de desigualdades, tem sido proposta, a partir da década passada, a implementação de políticas de ação afirmativa, com especial atenção para os programas de reservas de vagas (JACCOUD; THEODORO, 2005; GUIMARÃES, 2016).

Dos mais de 20 projetos de lei que tramitaram por mais de dez anos no Congresso Nacional visando à instituição de ações afirmativas nas instituições de educação superior, um deles - o PL n. 73/1999 - acabou por ser finalmente aprovado na forma da Lei n. 12.711, de 29 de agosto de 2012, que rapidamente ganhou a alcunha de Lei de Cotas. Trata-se, em suma, de uma norma federal que define parâmetros inclusivos, por meio da reserva de vagas, para o acesso às Instituições Federais de Educação Superior (Ifes) e aos institutos federais de ensino técnico de nível médio vinculados ao Ministério da Educação (MEC). O sistema de reserva de vagas para acesso a elas, no escopo da legislação vigente, obedece a um misto de critérios em que o atendimento a um está condicionado ao cumprimento de outro. Na prática, a Lei prevê, primeiramente, que 50\% das vagas por instituição, curso e turno devam se destinar aos alunos que estudaram na rede pública durante toda sua escolarização em nível médio. ${ }^{2}$ Em seguida, estabelece uma segunda reserva de vagas, dentro do primeiro contingente, voltada para outras duas condições: uma proporção mínima de 50\% de estudantes oriundos de famílias cuja renda mensal per capita é igual ou inferior a 1,5 salário-mínimo; e uma proporção de autodeclarados pretos, pardos e indígenas (PPI) no mínimo igual à soma desses grupos na unidade da federação (UF) onde se encontra o referido estabelecimento de ensino. ${ }^{3}$

Além de abrangente, por mirar diferentes expressões das disparidades sociais, a Lei de Cotas pode ser considerada potencialmente importante como estratégia para reduzir a estratificação social no acesso à educação. É sabido, contudo, que a implantação da política nacional de reserva de vagas ocorreu, para inúmeras Ifes, em um cenário institucional já permeável à adoção de medidas de ação afirmativa. A julgar pelo levantamento realizado por Daflon, Feres Júnior e Campos (2013), viu-se que, até 2012, 70 de um total de 96 universidades estaduais e federais haviam implementado seus próprios programas de ação afirmativa, aprovados no âmbito de seus conselhos universitários atendendo a reivindicações sociais de distintas ordens, e apresentando parâmetros e formatos variados. Assim, mais do que inaugurar a ação afirmativa no acesso às universidades e

2 O Decreto n. 7.824/2012 igualmente habilita para a concorrência às vagas reservadas aos estudantes que tenham concluído o ensino médio com base em exames de certificação nacionais ou estaduais.

3 Acrescenta-se que a Lei n. 13.409/2016 adicionou aos critérios para delimitação dos beneficiários um percentual de pessoas com deficiência similar ao da UF de referência. Porém, em razão de nossa ênfase sobre as desigualdades socioeconômicas e étnico-raciais, não abordaremos esse tópico neste texto. 
institutos federais, a Lei de Cotas foi responsável por homogeneizar os critérios mínimos para reserva de vagas, estendendo-os a todas as Ifes; essa constatação não nos impede de reconhecer, segundo Carvalhaes, Feres Júnior e Daflon (2013), que os impactos da Lei de Cotas possam ser bastante diferenciados entre as UF.

Em contrapartida, essa legislação ainda carece de efetivos mecanismos que possibilitem seu monitoramento e avaliação. Desafios de ordem política, técnica e metodológica impuseram empecilhos ao processo de acompanhamento da execução, dos resultados e dos impactos dessa política sobre o perfil do campus brasileiro pelo território nacional. Não à toa, poucos são os estudos que, em âmbito nacional, têm trazido subsídios para o monitoramento e a avaliação da Lei por meio da proposição de indicadores sociais, da sistematização de dados nacionais e da publicação de estudos com diagnósticos amplos da reserva de vagas, conforme apontam Lazaro (2016) e Senkevics (2018). Acrescenta-se que já estamos no sétimo ano de vigência da Lei de Cotas, em cujo art. $7^{\circ}$ se prevê o prazo de dez anos para ser realizada uma revisão crítica desde sua implantação, e, até o momento, pouco se sabe acerca de sua eficácia e efetividade. Como a Lei foi implementada em cada uma das instituições de ensino superior brasileiras? Quão adequados são seus critérios em face das heterogeneidades e desigualdades regionais? Quais são as consequências da reserva de vagas para a alteração do perfil do campus brasileiro? Que mudanças seriam desejáveis visando aos resultados mais frutíferos para os próximos anos? Essas e outras perguntas restam em aberto, corroborando o argumento de que, a despeito de sua relevância, a Lei de Cotas segue pouco como objeto de avaliação, ao menos em âmbito nacional.

Em vista das considerações apresentadas, e com a finalidade de contribuir para a geração de subsídios ao monitoramento da Lei de Cotas, este estudo tem como objetivo analisar o perfil socioeconômico e racial dos ingressantes das Ifes entre 2012 e 2016, na perspectiva de promover um olhar sistêmico sobre essa legislação, mediante o cruzamento de bases de dados oficiais em âmbito individual. Com isso, esta pesquisa tem a intenção de oferecer, em caráter exploratório, um retrato de abrangência nacional dos resultados e tendências da Lei de Cotas sobre o corpo discente da rede federal de educação superior.

\section{MÉTODO E TÉCNICAS}

Este estudo, de natureza quantitativa, se baseou no tratamento, cruzamento e análise de diferentes edições de duas pesquisas do Instituto Nacional de Estudos e Pesquisas Educacionais Anísio Teixeira (Inep): as bases de dados relativas aos ingressantes dos cursos presenciais de graduação em Ifes no Censo da Educação Superior (CES) e as bases de dados relativas aos inscritos no Exame Nacional do Ensino Médio (Enem). Tratam-se, respectivamente, de um levantamento censitário de matrículas, cursos, funções docentes e instituições em nível superior, e de um exame em larga escala aplicado todos os anos principalmente a egressos e concluintes do ensino médio com a finalidade maior de subsidiar o processo seletivo de ingressantes ao ensino superior público e privado. Ao passo que o 
primeiro é informado anualmente ao Inep por representantes dos estabelecimentos de ensino, os quais preenchem um sistema com informações sobre cada uma das matrículas, o segundo é autopreenchido pelos candidatos no ato da inscrição e contém, além do formulário de inscrição, um questionário socioeconômico.

O propósito de junção das bases se sustenta porque, apesar de o CES apresentar dados censitários sobre as matrículas de ingressantes, o cruzamento com os dados do Enem se mostrou indispensável para a composição das variáveis de análise, pelas três razões a seguir: (1) notamos ser insuficiente utilizar a variável indicadora da procedência escolar dos discentes (i.e. se oriundo das redes pública ou privada) no CES, dado que a procedência escolar no Enem explicitamente indica se o estudante cursou todo o ensino médio em escola pública, como exigido; ${ }^{4}$ (2) há notável subnotificação do quesito cor/raça no mesmo levantamento, que variou de 56\% dos ingressantes em 2012 para 16\% em 2016, ao passo que o Enem obtém dados raciais para quase a totalidade dos inscritos (para uma revisão, ver SENKEVICS; MACHADO; OLIVEIRA, 2016); (3) não há variável de renda familiar per capita no CES, motivo pelo qual tivemos que compô-la com base no questionário socioeconômico do Enem. Explicamos, no Quadro 1, como foram compostas as três principais variáveis exploradas neste estudo.

\section{QUADRO 1}

\section{DESCRIÇÃO DAS VARIÁVEIS CONSTRUÍDAS PARA O ESTUDO}

\begin{tabular}{|l|l|l|}
\hline \multicolumn{1}{|c|}{ VARIÁVEL } & \multicolumn{1}{|c|}{$\begin{array}{c}\text { FONTE DE } \\
\text { DADOS }\end{array}$} & \multicolumn{1}{c|}{ PROCEDIMENTOS PARA SUA COMPOSIÇÃo } \\
\hline $\begin{array}{l}\text { Procedência } \\
\text { escolar }\end{array}$ & Enem e CES & $\begin{array}{l}\text { Variável construída com base na questão "em que tipo } \\
\text { de escola você frequentou o ensino médio" (Enem), } \\
\text { complementada pela variável relativa à procedência } \\
\text { escolar dos ingressantes (CES), desde que esta tenha sido } \\
\text { considerada consistente.* }\end{array}$ \\
\hline Cor/raça & Enem e CES & $\begin{array}{l}\text { Variável obtida com base na declaração racial no Enem, } \\
\text { complementada pela declaração racial no CES, em caso } \\
\text { de ausência da primeira. As opções "preto", "pardo" e } \\
\text { "indígena" foram agregadas para definir a categoria PPI; } \\
\text { respostas inválidas foram recodificadas para uma única } \\
\text { categoria não declaratória. }\end{array}$ \\
\hline $\begin{array}{l}\text { Renda familiar per } \\
\text { capita }\end{array}$ & Enem & $\begin{array}{l}\text { Variável definida dividindo-se o limite superior das faixas } \\
\text { de renda do questionário socioeconômico pelo número de } \\
\text { habitantes no domicílio e indicando-se rendas familiares } \\
\text { iguais ou inferiores a 1,5 salário-mínimo (SM) per capita. }\end{array}$ \\
\hline
\end{tabular}

* Considerou-se inconsistente se, simultaneamente, (a) a proporção de alunos oriundos de escolas públicas por instituição fosse menor que $25 \%$ ou maior que $80 \%$ e (b) a diferença entre as médias por instituição/ano da proporção de alunos de escolas públicas das variáveis originais do Enem e do CES fosse maior que 5 p.p. Tais critérios foram definidos empiricamente a fim de minimizar viéses na composição da variável.

Fonte: Elaboração própria com base em dados do Enem e CES (Inep).

Com o intuito de construir as bases de dados para este estudo, adaptou-se a metodologia adotada por Senkevics (2018) e Rabelo (2017). Para elaborar a base de dados dos ingressantes das Ifes, considerando a junção do CES com os dados dos inscritos em diferentes edições do Enem, lançamos mão dos seguintes passos, 
realizados por meio do programa SAS Enterprise Guide, versão 4.2: primeiramente, preparamos cinco bases distintas de ingressantes das Ifes no CES, uma para cada ano (de 2012 a 2016), com informações sobre características individuais dos estudantes e dos cursos de graduação presenciais por eles frequentados. Optamos por restringir nossas análises a partir da edição de 2012 do CES, pois a sanção e vigência da Lei de Cotas data desse mesmo ano - entendemos, portanto, que 2012 é a linha de base para o nosso estudo -, e as estendemos até 2016 por ser o prazo final de implantação da referida legislação, além de ser o ano mais recente para o qual existiam dados publicados quando do desenvolvimento desta pesquisa.

Em seguida, preparamos cinco bases distintas do Enem, uma para cada edição (de 2011 a 2015), com informações obtidas pelo formulário de inscrição e pelo questionário socioeconômico preenchido pelos inscritos. Finalmente, utilizamos o Cadastro de Pessoa Física (CPF) como chave de ligação entre as bases de dados, permitindo que se identificassem os mesmos estudantes a fim de fundir informações das duas bases de dados. Fundamentando-se nessa variável, procuramos localizar os mesmos indivíduos na base de dados da edição do Enem imediatamente anterior a cada uma das edições do CES - por exemplo, para os ingressantes de 2016, seus CPF foram utilizados como chave de ligação para a edição de 2015 do Enem. Após os cruzamentos, empilhamos as bases de dados com o intuito de gerar painéis longitudinais, para os distintos níveis de agregação, no formato long ou univariado (cf. SINGER; WILLET, 2003).

O universo de análise dos dados foi delimitado para os alunos ingressantes dos cursos de graduação na modalidade presencial das 104 Ifes vinculadas ao MEC, que variou de 300 mil matrículas de ingressantes em 2012 para 327 mil em 2016 (Tabela 1). Igualmente, nota-se que quanto mais recente a edição do CES, maior o percentual de matrículas localizadas na edição respectivamente anterior do Enem. Finalmente, as bases de dados já cruzadas e tratadas foram analisadas utilizando-se os pacotes estatísticos Stata, versão 12.1, e Microsoft Excel 2016.

TABELA 1

QUANTIDADE DE MATRÍCULAS DE INGRESSANTES CONSIDERADAS NO ESTUDO - BRASIL - 2012-2016

\begin{tabular}{|c|c|c|}
\hline ANO & $\begin{array}{c}\text { MATRÍCULAS DE } \\
\text { INGRESSANTES NO CES }\end{array}$ & $\begin{array}{c}\text { MATRÍCULAS } \\
\text { LOCALIZADAS NO ENEM }\end{array}$ \\
\hline \multirow{2}{*}{2012} & \multirow{2}{*}{300.051} & 243.556 \\
\hline & & $81 \%$ \\
\hline \multirow{2}{*}{2013} & \multirow{2}{*}{298.788} & 251.349 \\
\hline & & $84 \%$ \\
\hline \multirow{2}{*}{2014} & \multirow{2}{*}{311.069} & 265.787 \\
\hline & & $85 \%$ \\
\hline \multirow{2}{*}{2015} & \multirow{2}{*}{321.623} & 280.279 \\
\hline & & $87 \%$ \\
\hline \multirow{2}{*}{2016} & \multirow{2}{*}{327.020} & 288.222 \\
\hline & & $88 \%$ \\
\hline \multirow{2}{*}{ Total } & \multirow{2}{*}{1.558 .551} & 1.329 .193 \\
\hline & & $85 \%$ \\
\hline
\end{tabular}

Fonte: Elaboração própria com base em dados do CES 2012-2016 e Enem 2011-2015 (Inep). 
Como fontes complementares de dados, e com o intuito de compor uma visão geral do acesso ao ensino superior público federal entre jovens de 18 a 24 anos, realizamos análises descritivas dos microdados do Censo Demográfico 2010 e da Pesquisa Nacional por Amostra de Domicílio Contínua (Pnad-c) 2012/2016, ambos de responsabilidade do Instituto Brasileiro de Geografia e Estatística (IBGE). Ademais, para possibilitar certas análises em âmbito institucional, utilizamos os resultados do Índice Geral de Cursos Avaliados da Instituição (IGC) de 2016, ${ }^{5}$ indicador de qualidade das instituições de educação superior calculado anualmente pelo Inep com base nas notas contínuas dos Conceitos Preliminares de Curso (CPC) dos cursos de graduação do último triênio e do Conceito Capes dos cursos de pós-graduação stricto sensu do mesmo estabelecimento, ponderados pelo número de matrículas dos cursos avaliados. Esse índice varia em uma escala de 1 a 5 e foi empregado neste estudo como uma referência de universidades mais ou menos bem-conceituadas de acordo com os critérios oficiais de avaliação institucional (Cf. VERHINE; DANTAS, 2009; IKUTA, 2016).

Por fim, para a utilização de uma informação pessoal sensível (no caso, o CPF dos ingressantes), foi obtida a autorização formal do Inep no âmbito da Portaria n. 465, de 31 de maio de 2017, que permite o uso dessas informações para estudos com fins científicos e assevera que os resultados divulgados não identifiquem os sujeitos presentes em tais bases de dados. Nesse sentido, é importante frisar que os resultados aqui apresentados estão em conformidade com esses preceitos legais e éticos, na medida em que preservam o sigilo das informações pessoais e a identificação dos estudantes. Ainda, é válido ressaltar que o CPF dos indivíduos foi utilizado exclusivamente como chave de ligação para o cruzamento de dados, tendo sido excluído tão logo compusemos a base para fins analíticos.

\section{O QUE MUDOU NO PERFIL DISCENTE APÓS A LEI DE COTAS?}

Para a exposição dos resultados, dividiremos esta seção em três partes. Na primeira, realizaremos uma análise geral em âmbito nacional e explorando desagregações por grandes regiões e UF. Em seguida, atentaremos a uma visão geral das trincas Instituição-Curso-Turno, entendida como a menor unidade de aplicação da Lei de Cotas. Por fim, a terceira parte aborda os resultados gerais da Lei de Cotas sobre o conjunto das Ifes vinculadas ao MEC e, em paralelo, uma análise comparada da reserva de vagas sobre um grupo selecionado de Ifes, procurando cobrir instituições que apresentem diferentes valores para o IGC 2016 em todas as grandes regiões do país. 


\section{ENSINO SUPERIOR ANTES E DEPOIS DA LEI DE COTAS}

Apesar de as primeiras experiências de políticas de ação afirmativa no ensino superior público no Brasil datarem de 2003, quando universidades estaduais do Rio de Janeiro foram pioneiras na adoção da reserva de vagas em seus vestibulares de ingresso, e terem sido acompanhadas por uma progressiva implantação dessas medidas em outras universidades pelo país afora, a participação de grupos sociais mais vulneráveis nas Ifes restava, ainda em 2012, substancialmente diminuto em relação à sua presença na população brasileira.

A Tabela 2 compara dados referentes à composição demográfica de jovens de 18 a 24 anos na população de cada grande região e do Brasil com aqueles relativos a jovens de 18 a 24 anos ingressantes nas Ifes. Observa-se que, em 2012, a população brasileira de tal faixa etária era composta por 32\% de brancos e amarelos de baixa renda, 50\% de PPI de baixa renda e 18\% de jovens (independentemente da cor ou raça) com rendas familiares superiores a 1,5 salário-mínimo per capita. Entretanto, entre os ingressantes das Ifes, os percentuais eram, respectivamente, 37, 34 e 29\%. Evidencia-se, assim, que o grupo de PPI de baixa renda era substancialmente sub-representado em 2012, ano anterior à implementação da Lei de Cotas. Em 2016, após a implementação integral da Lei, a participação dos PPI de baixa renda cresceu 8,8 p.p. Comparativamente, enquanto a proporção desse grupo demográfico cresceu $8 \%$ na população total, o crescimento na população de ingressantes das Ifes foi de $26 \%$.

\section{TABELA 2}

PARTICIPAÇÃO (\%) DOS JOVENS DE 18-24 ANOS, POR COR/RAÇA E RENDA FAMILIAR, NA POPULAÇÃO E NAS IFES - BRASIL E GRANDES REGIÕES - 2012/2016

\begin{tabular}{|c|c|c|c|c|c|c|c|c|c|c|c|c|}
\hline & \multicolumn{4}{|c|}{$\begin{array}{l}\text { BRANCOS E AMARELOS } \\
\text { COM RENDA } \leq 1,5 \text { SM }\end{array}$} & \multicolumn{4}{|c|}{$\begin{array}{l}\text { PRETOS, PARDOS } \\
\text { E INDÍGENAS COM } \\
\text { RENDA } \leq 1,5 \text { SM }\end{array}$} & \multicolumn{4}{|c|}{$\begin{array}{l}\text { INDEPENDENTE DE COR/ } \\
\text { RAÇA, COM RENDA >1,5 SM }\end{array}$} \\
\hline & \multicolumn{2}{|c|}{2012} & \multicolumn{2}{|c|}{2016} & \multicolumn{2}{|c|}{2012} & \multicolumn{2}{|c|}{2016} & \multicolumn{2}{|c|}{2012} & \multicolumn{2}{|c|}{2016} \\
\hline & TOTAL & IFES & TOTAL & IFES & TOTAL & IFES & TOTAL & IFES & TOTAL & IFES & TOTAL & IFES \\
\hline Norte & 16,6 & 22,3 & 16,7 & 15,9 & 72,8 & 61,5 & 75,3 & 70,4 & 10,6 & 16,2 & 8,0 & 13,7 \\
\hline Nordeste & 20,8 & 30,2 & 22,1 & 23,4 & 72,1 & 48,9 & 72,8 & 60,2 & 7,1 & 20,9 & 5,1 & 16,4 \\
\hline Sudeste & 37,4 & 38,7 & 35,4 & 33,0 & 40,5 & 25,8 & 46,3 & 34,7 & 22,1 & 35,5 & 18,3 & 32,3 \\
\hline Sul & 54,4 & 56,2 & 55,5 & 50,7 & 17,8 & 10,0 & 21,5 & 16,8 & 27,8 & 33,8 & 23,0 & 32,5 \\
\hline Centro-Oeste & 24,2 & 32,8 & 26,2 & 26,6 & 51,6 & 34,6 & 56,0 & 41,4 & 24,2 & 32,6 & 17,8 & 32,0 \\
\hline Brasil & 32,1 & 37,0 & 31,7 & 30,9 & 50,2 & 33,9 & 54,3 & 42,7 & 17,7 & 29,1 & 14,0 & 26,4 \\
\hline
\end{tabular}

Legenda: SM = salário-mínimo per capita.

Fonte: Elaboração própria com base em dados do Pnad-c 2012/2016 (IBGE), CES 2012/2016 e Enem 2011/2015 (Inep).

A mesma tabela também evidencia a heterogeneidade geográfica existente entre as grandes regiões do país e a evolução entre a participação dos grupos em cada uma delas. O maior aumento absoluto da participação de PPI de baixa renda foi de 11,3 p.p. no Nordeste. Já o maior aumento relativo foi de $68 \%$ na região Sul; entretanto, tal região possui uma proporção de PPI de baixa renda bastante inferior àquela das demais regiões brasileiras. Cabe ressaltar que o diferencial relativo 
entre a participação do grupo de PPI de baixa renda na população e nas Ifes, ${ }^{6}$ entre 2012 e 2016, reduziu-se em todas as grandes regiões, tendo sido a maior redução de 57\% na região Norte, seguida de $46 \%$ no Nordeste, $40 \%$ na região Sul, $21 \%$ no Sudeste e 14\% no Centro-Oeste. Em âmbito nacional, essa redução foi de $29 \%$, dado que a distância entre o percentual de PPI de baixa renda na população e nas Ifes caiu de 16,3 p.p., em 2012, para 11,6 p.p., em 2016.

Analogamente, na Tabela 3, apresentam-se dados comparativos entre a composição do grupo de jovens PPI de 18 a 24 anos na população e nas Ifes por UF. Todas as UF, com exceção da Bahia, registraram aumento da participação desse grupo entre os ingressantes de 18 a 24 anos. O maior aumento absoluto foi de 20 p.p. no Ceará, enquanto o maior aumento relativo foi de $103 \%$ em Santa Catarina. Comparando o diferencial entre a participação na população e nas Ifes, entre 2012 e 2016, as maiores reduções relativas foram Santa Catarina (91\%) - que resultou na quase eliminação da desigualdade -, Tocantins (86\%) e Ceará (77\%). Em Roraima, Sergipe e no Distrito Federal, apesar do aumento absoluto da participação de jovens PPI de baixa renda nas Ifes, o crescimento do grupo na população da UF foi mais do que proporcional, o que resultou em diminutos aumentos em sua sub-representação. Por fim, Rondônia destaca-se por ser a única UF em que os jovens PPI de baixa renda são sobrerrepresentados nas Ifes.

\section{TABELA 3}

PARTICIPAÇÃO (\%) DOS JOVENS DE 18-24 ANOS, PPI E DE BAIXA RENDA, NA POPULAÇÃO E NAS IFES, POR UF - BRASIL - 2012/2016

\begin{tabular}{|c|c|c|c|c|c|c|c|c|c|}
\hline & \multicolumn{2}{|c|}{2012} & \multicolumn{2}{|c|}{2016} & & \multicolumn{2}{|c|}{2012} & \multicolumn{2}{|c|}{2016} \\
\hline & TOTAL & IFES & TOTAL & IFES & & TOTAL & IFES & TOTAL & IFES \\
\hline Rondônia & 58,7 & 54,0 & 63,2 & 66,7 & Sergipe & 72,0 & 65,1 & 74,6 & 67,4 \\
\hline Acre & 71,6 & 62,9 & 76,6 & 71,9 & Bahia & 77,3 & 64,8 & 79,4 & 62,2 \\
\hline Amazonas & 75,7 & 55,1 & 77,5 & 69,4 & Minas Gerais & 51,7 & 28,5 & 55,9 & 38,3 \\
\hline Roraima & 68,5 & 60,7 & 74,5 & 65,3 & Espírito Santo & 49,9 & 33,8 & 61,6 & 42,1 \\
\hline Pará & 75,2 & 68,5 & 76,9 & 72,4 & Rio de Janeiro & 50,2 & 23,7 & 54,6 & 32,8 \\
\hline Amapá & 76,3 & 61,3 & 74,3 & 65,0 & São Paulo & 30,6 & 16,9 & 36,9 & 23,1 \\
\hline Tocantins & 68,7 & 54,4 & 73,7 & 71,7 & Paraná & 25,2 & 12,1 & 29,5 & 19,8 \\
\hline Maranhão & 79,2 & 55,6 & 78,5 & 66,8 & Santa Catarina & 10,3 & 7,0 & 14,5 & 14,2 \\
\hline Piauí & 74,8 & 58,6 & 77,0 & 71,0 & Rio Grande do Sul & 14,4 & 9,9 & 17,3 & 15,9 \\
\hline Ceará & 69,6 & 45,8 & 70,9 & 65,4 & Mato Grosso do Sul & 46,4 & 29,6 & 50,8 & 39,8 \\
\hline Rio Grande do Norte & 60,4 & 33,9 & 60,3 & 49,2 & Mato Grosso & 57,8 & 45,6 & 62,4 & 50,0 \\
\hline Paraíba & 68,6 & 45,1 & 61,1 & 55,0 & Goiás & 55,3 & 37,4 & 57,6 & 46,3 \\
\hline Pernambuco & 64,8 & 42,2 & 68,2 & 53,2 & Distrito Federal & 41,5 & 27,7 & 50,0 & 32,7 \\
\hline Alagoas & 75,6 & 47,8 & 73,3 & 63,9 & & & & & \\
\hline
\end{tabular}

Fonte: Elaboração própria com base em dados do Pnad-c 2012/2016 (IBGE), CES 2012/2016 e Enem 2011/2015 (Inep). 
Na Tabela 4, pode-se observar a evolução da composição dos ingressantes nas Ifes, por categoria contemplada pela Lei de Cotas. Evidencia-se um aumento progressivo da participação de todos os potenciais beneficiários da ação afirmativa. Entre 2012 e 2016, a participação de estudantes provenientes do ensino médio em escolas públicas nas Ifes passou de 55,4 para 63,6\% (crescimento de $15 \%$ ), enquanto a participação de estudantes PPI de escolas públicas passou de 27,7 para 38,4\% (aumento de 39\%). O aumento da participação dos indivíduos de famílias com rendimentos inferiores a 1,5 salário-mínimo per capita foi bastante similar ao dos respectivos grupos sem o critério de renda.

TABELA 4

PARTICIPAÇÃO (\%) DOS GRUPOS BENEFICIÁRIOS DA LEI DE COTAS ENTRE OS INGRESSANTES DAS IFES - BRASIL - 2012-2016

\begin{tabular}{c|c|c|c|c}
\hline ANO & EP & EP E PPI & $\begin{array}{c}\text { EP E } \\
\text { RENDA } \leq 1,5 \text { SM }\end{array}$ & $\begin{array}{c}\text { EP, PPI E } \\
\text { RENDA } \leq 1,5 \text { SM }\end{array}$ \\
\hline 2012 & 55,4 & 27,7 & 48,2 & 24,9 \\
\hline 2013 & 56,7 & 29,9 & 48,6 & 26,8 \\
\hline 2014 & 58,5 & 33,2 & 50,4 & 29,4 \\
\hline 2015 & 62,2 & 34,4 & 52,0 & 29,9 \\
\hline 2016 & 63,6 & 38,4 & 54,8 & 34,0 \\
\hline
\end{tabular}

Legenda: EP = escola pública; PPI = pretos, pardos e indígenas; SM = salário-mínimo per capita.

Fonte: Elaboração própria com base em dados do CES 2012-2016 e Enem 2011-2015 (Inep).

Para avançar na compreensão desses números, a Tabela 5 traz um retrato atual da composição demográfica das Ifes, comparando dados dos ingressantes de 2016, após a implementação da Lei de Cotas, com um grupo demográfico similar no país e por grandes regiões. Utilizou-se, como grupo comparativo, os jovens de 16 a 18 anos que frequentam o ensino médio - vale lembrar que os jovens que alcançam, e principalmente os que concluem, o ensino médio no Brasil são bastante selecionados, de modo que tendem a ser excluídos os jovens de condições socioeconômicas mais vulneráveis (CORBUCCI, 2014; SIMÕES, 2016).

Observa-se, por exemplo, que cerca de $86,5 \%$ dos jovens brasileiros que frequentaram o ensino médio em 2016 o fizeram em escolas públicas, entretanto, mesmo após a implementação da Lei de Cotas, apenas 63,6\% dos ingressantes das Ifes cursaram o ensino médio na rede pública. Analogamente, vê-se que apenas $38,4 \%$ dos ingressantes nas Ifes são PPI que frequentaram escolas públicas, enquanto 54,1\% dos jovens brasileiros que frequentaram o ensino médio são desse mesmo grupo demográfico. Além das evidentes diferenças regionais, a Tabela 5 chama atenção ainda para as diferenças obtidas entre os grupos de comparação caso a Pnad-c 2016 seja adotada no lugar do Censo Demográfico 2010. De acordo com a legislação em tela, o parâmetro para a composição racial definido pela Lei de Cotas se baseia na proporção da população do respectivo grupo racial de acordo com o último recenseamento demográfico disponível. Entretanto, observa-se que, segundo a Pnad-c 2016, a participação de PPI aumentou desproporcionalmente em todas as grandes regiões, se comparada ao aumento da participação de 
estudantes de escolas públicas, por exemplo. O objetivo deste texto não é discutir as causas por trás desse fenômeno, mas ressaltar que, como critério para delimitação da reserva de vagas, a atualização do critério racial por meio da utilização de dados demográficos mais recentes talvez seja interessante do ponto de vista da garantia da equidade racial.

TABELA 5

PARTICIPAÇÃO (\%) DOS GRUPOS BENEFICIÁRIOS DA LEI DE COTAS NAS IFES E ENTRE JOVENS DE 16-18 ANOS QUE FREQUENTAM O ENSINO MÉDIO - BRASIL E GRANDES REGIÕES - 2016

\begin{tabular}{|c|c|c|c|c|c|}
\hline FONTE DE DADOS & SEGMENTO & EP & EP E PPI & $\begin{array}{c}\text { EP } E \\
\text { RENDA } \leq 1,5 \text { SM }\end{array}$ & $\begin{array}{c}\text { EP, PPI E } \\
\text { RENDA } \leq 1,5 \text { SM }\end{array}$ \\
\hline \multicolumn{6}{|c|}{ Brasil } \\
\hline CES 2016 + ENEM 2015 & Ifes & 63,6 & 38,4 & 54,8 & 34,0 \\
\hline Pnad-c 2016 & EM & 86,5 & 54,1 & 81,0 & 52,2 \\
\hline Censo Demográfico 2010 & EM & 85,2 & 47,5 & 73,9 & 43,4 \\
\hline \multicolumn{6}{|c|}{ Norte } \\
\hline CES 2016 + ENEM 2015 & Ifes & 75,3 & 62,7 & 69,5 & 57,9 \\
\hline Pnad-c 2016 & EM & 93,0 & 77,8 & 88,8 & 74,6 \\
\hline Censo Demográfico 2010 & EM & 91,0 & 69,2 & 82,2 & 63,5 \\
\hline \multicolumn{6}{|c|}{ Nordeste } \\
\hline CES 2016 + ENEM 2015 & Ifes & 63,3 & 48,1 & 58,5 & 44,8 \\
\hline Pnad-c 2016 & EM & 90,1 & 70,9 & 88,7 & 69,9 \\
\hline Censo Demográfico 2010 & EM & 86,2 & 61,8 & 82,4 & 59,4 \\
\hline \multicolumn{6}{|c|}{ Sudeste } \\
\hline CES 2016 + ENEM 2015 & Ifes & 58,6 & 32,8 & 48,1 & 27,6 \\
\hline Pnad-c 2016 & EM & 82,5 & 46,7 & 76,5 & 44,7 \\
\hline Censo Demográfico 2010 & EM & 83,5 & 41,8 & 69,8 & 37,1 \\
\hline \multicolumn{6}{|c|}{ Sul } \\
\hline CES 2016 + ENEM 2015 & Ifes & 66,3 & 17,5 & 53,0 & 14,2 \\
\hline Pnad-c 2016 & EM & 86,5 & 22,8 & 74,8 & 20,8 \\
\hline Censo Demográfico 2010 & EM & 86,1 & 19,8 & 66,6 & 17,2 \\
\hline \multicolumn{6}{|c|}{ Centro-Oeste } \\
\hline CES 2016 + ENEM 2015 & Ifes & 62,4 & 39,9 & 51,9 & 33,3 \\
\hline Pnad-c 2016 & EM & 87,1 & 59,3 & 79,4 & 55,0 \\
\hline Censo Demográfico 2010 & EM & 83,4 & 51,7 & 69,2 & 44,4 \\
\hline
\end{tabular}

Legenda: EP = escola pública; PPI = pretos, pardos e indígenas; $\mathrm{SM}$ = salário-mínimo per capita; EM = ensino médio.

Nota: A linha "CES 2016 + ENEM 2015” expressa o perfil dos ingressantes das Ifes. Já as linhas “Pnad-c 2016” e "Censo Demográfico 2010" indicam o perfil dos jovens de 16 a 18 anos no ensino médio.

Fonte: Elaboração própria com base em dados do CES 2016 e Enem 2015 (Inep), Pnad-c 2016 e Censo Demográfico 2010 (IBGE).

A breve análise desta seção nos possibilita traçar importantes conclusões a respeito do perfil discente das Ifes e de como a Lei de Cotas pode ter contribuído para a alteração deste. A primeira conclusão relevante é que se observou um aumento da participação de todos os grupos contemplados pela Lei de Cotas nas instituições federais. O grupo mais beneficiado, entre 2012 e 2016, foi o de 
indivíduos PPI de escolas públicas. Constatou-se, também, um aumento da participação de indivíduos de escolas públicas independentemente da cor ou raça, porém em proporção inferior àquele observado para os PPI. O aumento da participação de estudantes de baixa renda segundo o critério adotado pela Lei de Cotas, isto é, estudantes de famílias com rendimento familiar per capita igual ou inferior a 1,5 salário-mínimo, ocorreu de forma análoga ao aumento da participação de estudantes de faixas superiores da renda familiar per capita. Isso, provavelmente, deve-se à utilização de um critério excessivamente abrangente de renda; a título de ilustração, de acordo com os dados dos CES 2012-2016 cruzados com os do Enem 2011-2015, 77\% dos ingressantes das Ifes provêm de famílias com rendimento domiciliar per capita igual ou inferior a 1,5 salário-mínimo. Assim, com o intuito de se aumentar a participação dos indivíduos mais pobres, talvez seja o caso de revisar o critério de renda da Lei de Cotas, tópico que transcende os alcances deste texto e merece ulteriores estudos. Por fim, observa-se que, apesar do aumento da participação das categorias contempladas pela legislação em tela, tais grupos demográficos ainda se encontram sub-representados nas Ifes, quando comparados à sua participação na população brasileira. Dessa forma, conclui-se que, apesar dos avanços nos últimos anos, novas políticas são necessárias para a ampliação da equidade no acesso ao ensino superior público no Brasil.

\section{BREVE ANÁLISE DAS TRINCAS INSTITUIÇÃO-CURSO-TURNO}

Consideraremos como unidade de análise, nesta seção, as trincas formadas por Instituição-Curso-Turno, isto é, as combinações existentes entre cada curso de graduação oferecido nos turnos disponíveis de cada Ifes. Optamos por desenvolver tal análise em virtude de a Lei de Cotas regulamentar que a reserva de vagas se aplica a todos os cursos e turnos das Ifes vinculadas ao MEC. Embora seja fundamental, por serem as trincas as menores unidades de aplicação da referida lei, a análise detalhada da evolução do perfil discente que abrange as trincas esbarra em obstáculos metodológicos: os valores ausentes (missing values) e os erros de preenchimento referentes às variáveis de procedência escolar e cor/raça ${ }^{7}$ dos dados do CES e do Enem afetam, particularmente, as observações relacionadas às trincas, em virtude da maior desagregação e do menor número de observações.

Entretanto, em razão da importância de tal análise do ponto de vista da avaliação da política de reserva de vagas, optamos por mostrá-la no Gráfico 1. Neste, observa-se a distribuição da proporção de estudantes de escola pública e estudantes de escola pública PPI nas trincas ao longo do tempo. A amostra contém as trincas com mais de dez estudantes e para as quais possuímos ao menos $60 \%$ das informações referentes à procedência escolar e cor/raça, de forma a diminuir os problemas oriundos da subnotificação ou dos erros de preenchimento.

7 Por razões de espaço, não apresentaremos os resultados relativos à variável de renda familiar per capita para a análise das trincas Instituição-Curso-Turno. 

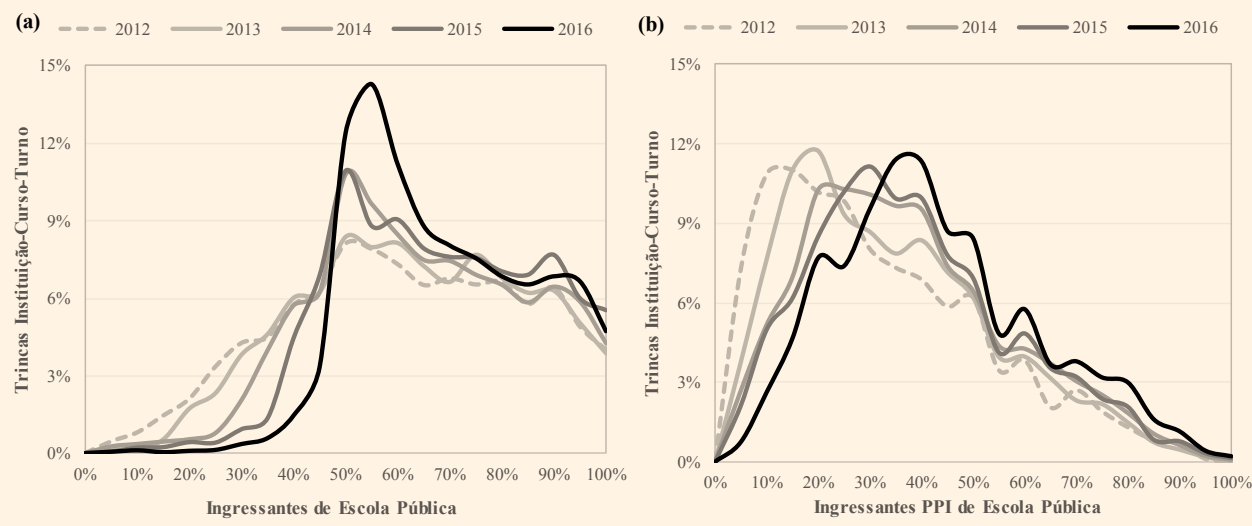

Legenda: $\mathrm{PPI}=$ pretos, pardos e indígenas.

Fonte: Elaboração própria com base em dados do CES 2012-2016 e Enem 2011-2015 (Inep).

Nota-se, claramente, um deslocamento progressivo da distribuição para os valores mais elevados, em ambos os gráficos, o que evidencia um aumento da participação dos dois grupos beneficiários pela Lei de Cotas ao longo de toda a distribuição das trincas. Tal observação é importante, na medida em que apresenta evidências sugestivas de que a Lei de Cotas tenha ampliado a participação dos estudantes de escolas públicas e negros/indígenas em instituições, cursos e turnos de diferentes níveis de competitividade e prestígio social. Com relação ao gráfico à esquerda, é possível perceber que a progressiva implantação da Lei eliminou substancialmente a cauda de distribuição inferior a 50\%, fenômeno compreensível considerando-se que a legislação vigente determina este como o patamar mínimo em cada unidade de aplicação.

Como já se antecipou, os problemas metodológicos mencionados anteriormente são patentes nos gráficos, já que se observa trincas com zero ou 100\% de estudantes de escolas públicas - fato bastante improvável. Tal problema, entretanto, concentra-se nas extremidades da distribuição observada no gráfico, de maneira que a principal conclusão da análise continua relevante. Em razão dessas limitações, não exploraremos resultados adicionais pelas referidas trincas.

\section{COMO AS INSTITUIÇÕES FEDERAIS FORAM AFETADAS PELA RESERVA DE VAGAS}

Sabendo que o locus de aplicação da Lei de Cotas são as Ifes, uma vez que são as instituições que definem, por meio de edital publicado anualmente, os pormenores do processo seletivo, deliberando inclusive como o desempenho dos candidatos no Enem será computado no cálculo das médias e consequentemente das notas de corte dos ingressantes em cada um dos cursos, uma análise institucional 
é essencial para compor um retrato do perfil discente antes e depois da política de reserva de vagas. De início, é importante chamar atenção para as distinções observadas entre as universidades e os institutos federais quanto à inclusão de estudantes oriundos da rede pública (Tabela 6).

TABELA 6

INGRESSANTES PROVENIENTS DA REDE PÚBLICA (\%) EM UNIVERSIDADES E INSTITUTOS FEDERAIS - BRASIL E GRANDES REGIÕES - 2012/2016

\begin{tabular}{l|c|c|c|c}
\hline \multirow{2}{*}{ REGIÃO } & \multicolumn{2}{|c|}{ UNIVERSIDADES } & \multicolumn{2}{c}{ INSTITUTOS FEDERAIS } \\
\cline { 2 - 5 } & $\mathbf{2 0 1 2}$ & $\mathbf{2 0 1 6}$ & $\mathbf{2 0 1 2}$ & $\mathbf{2 0 1 6}$ \\
\hline Norte & $\mathbf{7 1 , 2}$ & $\mathbf{7 4 , 1}$ & $\mathbf{7 9 , 5}$ & $\mathbf{8 3 , 2}$ \\
\hline Nordeste & 50,4 & 60,7 & 66,7 & 75,1 \\
\hline Sudeste & $\mathbf{4 8 , 2}$ & 55,4 & 63,0 & 71,0 \\
\hline Sul & 58,0 & 63,9 & 79,7 & 80,2 \\
\hline Centro-Oeste & 50,0 & 60,3 & 74,5 & 73,4 \\
\hline Total & $\mathbf{5 3 , 3}$ & $\mathbf{6 1 , 2}$ & $\mathbf{6 9 , 2}$ & $\mathbf{7 4 , 9}$ \\
\hline
\end{tabular}

Fonte: Elaboração própria com base em dados do CES 2012/2016 e Enem 2011/2015 (Inep).

Como se percebe, os institutos federais, em todas as grandes regiões do país, partem de valores, em 2012, superiores ao que as universidades alcançaram em 2016 em termos de participação de egressos do ensino médio público. Essas disparidades são particularmente acentuadas nas regiões Sul e Centro-Oeste e chegaram às diferenças absolutas de 15,8 e 14,2 p.p., respectivamente. Isso significa afirmar que os institutos federais, originalmente mais permeáveis à inclusão da população-alvo da Lei de Cotas, tornaram-se ainda mais inclusivos no período considerado. De toda sorte, essa constatação não nos exime de apontar que foram as universidades que sofreram as maiores variações relativas: entre 2012 e 2016, a presença desses estudantes aumentou 14,8\% entre as universidades e somente $8,2 \%$ entre os institutos federais.

Assim como se observou para as trincas, a Lei de Cotas mostrou-se bastante eficaz em eliminar a cauda inferior da distribuição, fixando o valor de $50 \%$ como o patamar mínimo para a participação de ingressantes oriundos de escolas públicas (Figura 1a). Também se constata que 77 das 104 Ifes já atendiam, em 2012, ao critério mínimo de metade de ingressantes provenientes da rede pública (Figura 1b). Destas, cerca de 60\% tiveram acréscimos na participação destes, ao passo que um quinto se manteve estagnado ${ }^{8}$ e outro quinto caiu. Se, por outro lado, atentarmos para as instituições que não atingiam o percentual mínimo de alunos de escola pública no primeiro ano da série histórica, vemos que quase a totalidade delas observou incrementos nesses valores, tendo alcançado pelo menos o patamar mínimo exigido pela Lei. À guisa de exemplo, a Universidade Federal 
de Itajubá (Unifei) saiu de 21,4\% em 2012 para 50,4\% em 2016, correspondendo a uma variação absoluta de 29 p.p., o maior crescimento observado no período.

\section{FIGURA 1}

(A) DISTRIBUIÇÃO PERCENTUAL DE INGRESSANTES DE ESCOLA PÚBLICA, POR INSTITUIÇÃO E (B) DIFERENÇA ENTRE ESSE PERCENTUAL NUM AGRUPAMENTO DAS 104 IFES - BRASIL - 2012/2016

(a)

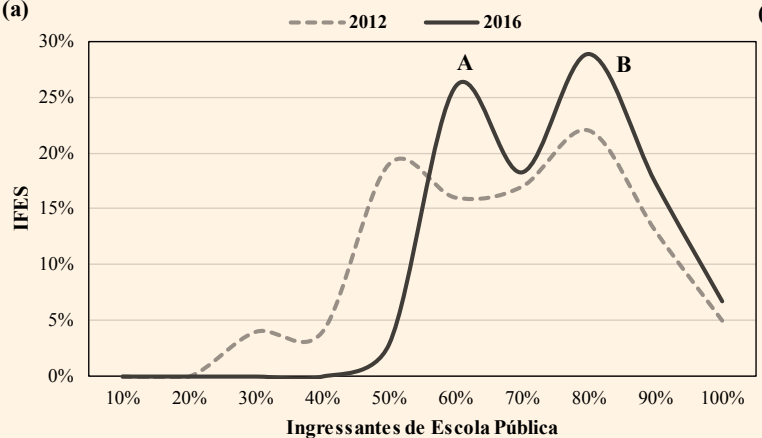

(b)

\begin{tabular}{c|l|c|c}
\hline $\begin{array}{c}\text { Condição inicial } \\
\text { (2012) }\end{array}$ & \multicolumn{1}{|c|}{$\begin{array}{c}\text { Diferença } \\
(\mathbf{2 0 1 6} \text { - 2012) }\end{array}$} & n & \% \\
\hline \multirow{3}{*}{$\begin{array}{c}\text { Escola Pública } \\
<50 \%\end{array}$} & Maior que 1 p.p. & 26 & 96,3 \\
& Entre -1 e 1 p.p. & 0 & 0,0 \\
& Menor que -1 p.p. & 1 & 3,7 \\
& Total & $\mathbf{2 7}$ & $\mathbf{1 0 0 , 0}$ \\
\hline \multirow{3}{*}{ Escola Pública } & Maior que 1 p.p. & 46 & 59,7 \\
$\geq 50 \%$ & Entre -1 e 1 p.p. & 16 & 20,8 \\
& Menor que -1 p.p. & 15 & 19,5 \\
& Total & $\mathbf{7 7}$ & $\mathbf{1 0 0 , 0}$ \\
\hline \hline
\end{tabular}

Fonte: Elaboração própria com base em dados do CES 2012/2016 e Enem 2011/2015 (Inep).

Em conjunto, esses fatores levaram à formação de uma distribuição bimodal, com um pico concentrado entre os 50 e $70 \%$, e outro pico entre os 70 e $90 \%$ de estudantes oriundos da rede pública. No primeiro pico (indicado pela letra A), estão presentes 49 Ifes, sendo quase metade delas da região Sudeste, um quarto do Nordeste e as demais distribuindo-se entre Sul e Centro-Oeste, com baixíssima participação do Norte. Importa notar que, dentro de algumas regiões, ou nos limites de um mesmo estado, coexistem instituições que abarcam públicos bastante distintos. O Rio Grande do Sul, por exemplo, comporta tanto a Universidade Federal de Ciências da Saúde de Porto Alegre (UFCSPA), que passou de 25,9 para $51,0 \%$ de ingressantes de escola pública, quanto o Instituto Federal Farroupilha (IF Farroupilha), que se manteve estável na casa dos 93,0\% de estudantes da mesma condição. Já no segundo pico (B), pouco mais da metade são Ifes nortistas e nordestinas, as quais se somam essencialmente a institutos federais dos demais estados.

Para escolher algumas instituições para a análise comparativa, selecionamos quatro Ifes de cada grande região - duas daquelas de maior valor do IGC 2016 e duas de menor valor dentro de sua respectiva região -, desde que as instituições cumprissem os seguintes requisitos: (1) sua organização acadêmica fosse universidade; (2) tivesse dados completos de 2012 a 2016; (3) não fossem selecionadas duas universidades da mesma UF dentro de cada subgrupo de desempenho no IGC; (4) apresentassem um número mínimo de dez cursos avaliados para o cômputo do indicador; (5) apresentassem um número mínimo de mil ingressantes em 2016. Na Tabela 7, exibimos os resultados obtidos. 
TABELA 7

INGRESSANTES PROVENIENTES DA REDE PÚBLICA (\%) EM IFES SELECIONADAS EM FUNÇÃO DO IGC 2016, POR GRANDES REGIÕES - BRASIL - 2012/2016

\begin{tabular}{|c|c|c|c|c|c|c|}
\hline \multirow[b]{2}{*}{ REGIÃO } & \multirow[b]{2}{*}{ IFES } & \multicolumn{3}{|c|}{ INGRESSANTES DE ESCOLAS PÚBLICAS (\%) } & \multirow{2}{*}{$\begin{array}{c}\text { IGC } \\
(2016)\end{array}$} & \multirow{2}{*}{$\begin{array}{c}\text { TOTAL DE } \\
\text { INGRESSANTES } \\
(2016)\end{array}$} \\
\hline & & 2012 & 2016 & $\begin{array}{l}\text { VARIAÇÃO } \\
\text { RELATIVA }\end{array}$ & & \\
\hline \multirow{4}{*}{ Norte } & UFPA & 70,4 & 63,8 & $-9,4$ & 3,14 & 7.333 \\
\hline & UFRA & 57,3 & 70,6 & 23,1 & 3,02 & 2.157 \\
\hline & UFOPA & 73,5 & 81,3 & 10,6 & 2,58 & 1.366 \\
\hline & UNIFAP & 74,9 & 58,5 & $-21,9$ & 2,46 & 1.957 \\
\hline \multirow{4}{*}{ Nordeste } & UFC & 28,4 & 56,9 & 100,5 & 3,79 & 7.925 \\
\hline & UFPE & 44,7 & 56,5 & 26,3 & 3,79 & 7.134 \\
\hline & UFPI & 47,8 & 66,1 & 38,5 & 2,83 & 6.105 \\
\hline & UFAL & 44,1 & 62,5 & 41,5 & 2,46 & 5.777 \\
\hline \multirow{4}{*}{ Sudeste } & UFMG & 47,9 & 55,2 & 15,3 & 4,23 & 7.469 \\
\hline & UFRJ & 44,8 & 50,3 & 12,3 & 4,11 & 9.838 \\
\hline & UFES & 54,3 & 55,0 & 1,2 & 3,34 & 4.964 \\
\hline & UFSJ & 60,4 & 60,2 & $-0,3$ & 3,21 & 2.843 \\
\hline \multirow{4}{*}{ Sul } & UFRGS & 47,6 & 55,9 & 17,5 & 4,30 & 7.054 \\
\hline & UFSC & 33,0 & 46,9 & 42,0 & 4,07 & 7.752 \\
\hline & UTFPR & 58,9 & 63,1 & 7,2 & 3,46 & 8.764 \\
\hline & Unipampa & 81,2 & 78,8 & $-2,9$ & 3,21 & 3.602 \\
\hline \multirow{4}{*}{ Centro-Oeste } & UnB & 35,1 & 49,7 & 41,6 & 3,96 & 9.840 \\
\hline & UFG & 47,2 & 58,0 & 22,8 & 3,43 & 6.979 \\
\hline & UFMS & 53,0 & 67,5 & 27,4 & 3,08 & 5.383 \\
\hline & UFMT & 67,6 & 69,3 & 2,5 & 3,05 & 5.822 \\
\hline
\end{tabular}

Fonte: Elaboração própria com base em dados do CES 2012/2016, Enem 2011/2015 e IGC 2016 (Inep).

Os dados permitem concluir que as maiores variações percentuais tendem a acontecer nas universidades originalmente mais elitizadas, as quais coincidem com aquelas mais bem-conceituadas na avaliação institucional. Na Universidade Federal do Ceará (UFC), por exemplo, dobrou-se o percentual de ingressantes da escola pública, tendo passado de 28,4\% em 2012 para 56,9\% em 2016. Outras variações importantes aconteceram na Universidade Federal de Santa Catarina (UFSC) e na Universidade de Brasília (UnB), que assistiram a crescimentos relativos superiores a $40 \%$ de seus respectivos valores originais. Por outro lado, não podemos deixar de reconhecer que algumas universidades de menor desempenho no IGC também sofreram variações consideráveis, em padrões por vezes contraditórios. Se, de um lado, a Universidade Federal do Mato Grosso do Sul (UFMS) observou um crescimento de $27,4 \%$ na participação de estudantes do ensino médio público, de outro, a Universidade Federal do Amapá (Unifap) sofreu um decréscimo de 21,9\% no mesmo percentual. Esse caso é um exemplo das 15 Ifes (Figura 1b) que já atendiam ao critério mínimo da Lei de Cotas e foram penalizadas pela reserva de vagas - discutiremos mais adiante possíveis razões para essa queda.

No Gráfico 2, atentamos às transformações no perfil dos ingressantes PPI oriundos de escola pública, em comparação aos ingressantes PPI de ambas as 
procedências escolares. Vê-se que, de uma curva com concentração de Ifes em valores inferiores a 50\% de ingressantes PPI de escola pública, passou-se para uma curva com maior dispersão em valores superiores da distribuição (Gráfico 2a). Quando observamos a curva de ingressantes PPI independentemente da procedência escolar (Gráfico 2b), notamos com mais clareza três porções da distribuição. Esses picos se expressavam de forma mais acentuada em 2012, porém foram substancialmente modificados com a reserva de vagas, que resultou em deslocamento da curva para os valores superiores e, assim, atenuou os dois primeiros picos.

\section{GRÁFICO 2} DISTRIBUIÇÃO PERCENTUAL DE INGRESSANTES (A) PPI DE ESCOLA PÚBLICA E (B) PPI
DE ESCOLA PÚBLICA OU PRIVADA, NAS IFES - BRASIL - 2012/2016
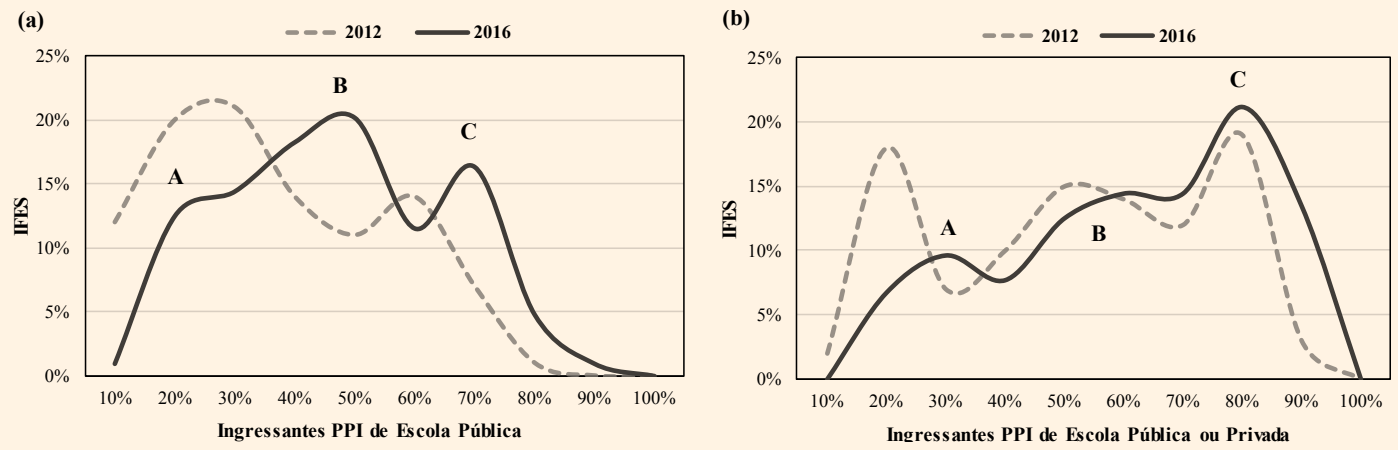

Fonte: Elaboração própria com base em dados do CES 2012/2016 e Enem 2011/2015 (Inep).

Com relação às instituições que ocupam tais faixas, o padrão é bastante similar entre os dois gráficos e pode ser assim sintetizado: na porção A, estão presentes todas as Ifes da região Sul e de São Paulo, além de algumas poucas de Minas Gerais e do Rio de Janeiro. A porção B reúne todas as Ifes do Centro-Oeste, a maior parte do Sudeste, algumas do Nordeste (em particular do Rio Grande do Norte, Paraíba, Pernambuco e Ceará) e poucas do Norte. Por fim, a porção C, que expressa a maior presença dos ingressantes PPI de suas respectivas procedências escolares, contém a maioria absoluta das Ifes do Nordeste e do Norte e uma participação residual de instituições mineiras. Dado que o critério étnico-racial depende da UF em que se localiza o respectivo estabelecimento de ensino, é esperado que as distintas universidades e institutos federais do país ocupem determinados nichos em termos de inclusão de negros e indígenas.

De toda forma, não resta dúvida de que houve crescimento na presença dos beneficiários das cotas dentro das instituições, fenômeno que pode ser atestado pelo número de Ifes que observou crescimento na participação de ingressantes PPI de escola pública (dados não apresentados): 98 instituições apresentaram variações superiores a 1 p.p. entre 2012 e 2016, quatro permaneceram estagnadas (UFPA, UFABC, UFRRJ e Unila) e somente duas sofreram reduções nesse percentual - Unifap e Instituto Nacional de Educação de Surdos (Ines) - e, mesmo assim, fecharam a série histórica com uma participação elevada dessa população: 48,2\% 
e 58,5\%, respectivamente. Como esperado, as variações relativas se distinguem bastante entre as regiões consideradas: na região Sul, a já mencionada UFCSPA observou uma elevação de 1,5\% de ingressantes PPI de escola pública em 2012 para 8,9\% em 2016 - por menor que possa parecer, essa elevação representa um aumento de seis vezes. Crescimentos substanciais na presença desses estudantes também aconteceram na Unifei (de 7,4 para 26,5\%) e na Universidade Federal do Estado do Rio de Janeiro - Unirio (de 8,5 para $28,8 \%$ ).

A Tabela 8 reitera a comparação entre as mesmas universidades da análise anterior, desta vez tomando como critério a procedência escolar e a cor/raça dos ingressantes.

TABELA 8

INGRESSANTES PPI PROVENIENTES DA REDE PÚBLICA (\%) EM IFES SELECIONADAS EM FUNÇÃO DO IGC 2016, POR GRANDES REGIÕES - BRASIL - 2012/2016

\begin{tabular}{|c|c|c|c|c|c|c|}
\hline \multirow{2}{*}{ REGIÃO } & \multirow{2}{*}{ IFES } & \multicolumn{3}{|c|}{$\begin{array}{l}\text { INGRESSANTES PPI DE } \\
\text { ESCOLAS PÚBLICAS (\%) }\end{array}$} & \multirow{2}{*}{$\begin{array}{l}\text { IGC } \\
(2016)\end{array}$} & \multirow{2}{*}{$\begin{array}{c}\text { TOTAL DE } \\
\text { INGRESSANTES } \\
(2016)\end{array}$} \\
\hline & & 2012 & 2016 & $\begin{array}{l}\text { VARIAÇÃO } \\
\text { RELATIVA }\end{array}$ & & \\
\hline \multirow{4}{*}{ Norte } & UFPA & 56,2 & 56,1 & $-0,3$ & 3,14 & 7.333 \\
\hline & UFRA & 45,9 & 58,9 & 28,3 & 3,02 & 2.157 \\
\hline & Ufopa & 55,3 & 69,5 & 25,7 & 2,58 & 1.366 \\
\hline & Unifap & 58,2 & 48,2 & $-17,2$ & 2,46 & 1.957 \\
\hline \multirow{4}{*}{ Nordeste } & UFC & 18,4 & 43,3 & 135,4 & 3,79 & 7.925 \\
\hline & UFPE & 25,8 & 38,8 & 50,1 & 3,79 & 7.134 \\
\hline & UFPI & 34,4 & 54,9 & 59,6 & 2,83 & 6.105 \\
\hline & Ufal & 29,6 & 48,6 & 64,2 & 2,46 & 5.777 \\
\hline \multirow{4}{*}{ Sudeste } & UFMG & 28,4 & 36,5 & 28,7 & 4,23 & 7.469 \\
\hline & UFRJ & 19,3 & 29,8 & 54,5 & 4,11 & 9.838 \\
\hline & Ufes & 27,8 & 34,0 & 22,1 & 3,34 & 4.964 \\
\hline & UFSJ & 26,0 & 33,6 & 29,5 & 3,21 & 2.843 \\
\hline \multirow{4}{*}{ Sul } & UFRGS & 8,7 & 15,6 & 78,4 & 4,30 & 7.054 \\
\hline & UFSC & 6,4 & 14,2 & 120,5 & 4,07 & 7.752 \\
\hline & UTFPR & 10,9 & 19,8 & 81,7 & 3,46 & 8.764 \\
\hline & Unipampa & 14,4 & 15,6 & 8,3 & 3,21 & 3.602 \\
\hline \multirow{4}{*}{ Centro-Oeste } & UnB & 17,5 & 32,5 & 85,6 & 3,96 & 9.840 \\
\hline & UFG & 26,0 & 38,9 & 50,0 & 3,43 & 6.979 \\
\hline & UFMS & 25,7 & 38,3 & 48,9 & 3,08 & 5.383 \\
\hline & UFMT & 43,0 & 48,0 & 11,7 & 3,05 & 5.822 \\
\hline
\end{tabular}

Fonte: Elaboração própria com base em dados do CES 2012/2016, Enem 2011/2015 e IGC 2016 (Inep).

Ademais, se compararmos as variações percentuais entre as Ifes dentro de cada grande região, verificaremos que tendem a ser maiores nas universidades de maior IGC. Isso significa que a Lei de Cotas pode estar impactando de forma mais intensa as instituições mais bem-conceituadas no sistema de avaliação da educação superior e que, talvez, tendam a ser as mais concorridas quanto ao ingresso e mais prestigiadas social e economicamente, ao menos entre parâmetros internos 
à sua própria grande região. Para novas pesquisas, permanece a indagação se o processo de inclusão aqui descrito teria impactado de forma diferencial ou não os cursos dentro de uma mesma instituição, abordagem que iluminaria aspectos de uma possível redução ou manutenção da estratificação horizontal no acesso a cursos de graduação.

Para terminar esta seção, vale explorar os resultados levando-se em conta o parâmetro socioeconômico. A Figura 2a demonstra que, ao contrário das anteriores, há maior sobreposição entre as curvas de 2012 e 2016, coerente com a constatação de que o critério de renda familiar tem sido pouco efetivo para a inclusão de estudantes de camadas populares, sugerindo, outrossim, que os segmentos de maiores rendimentos per capita possam ser desproporcionalmente beneficiados pela política de ação afirmativa (CARVALHAES; FERES JR.; DAFLON, 2013, p. 19). De notório, nossas análises mostram uma eliminação da cauda inferior da distribuição que, em 2012, continha instituições com menos de 30\% de ingressantes de escola pública e baixa renda. Com algum esforço, podemos distinguir duas porções da curva de 2016. A porção A abrange até $60 \%$ de ingressantes nessa condição e contempla, basicamente, a maioria das Ifes das regiões Sudeste, Sul e Centro-Oeste, com alguma participação do Nordeste e somente uma universidade do Norte. E a porção B, por sua vez, contém a maioria das Ifes do Norte e Nordeste e menos da metade das instituições das demais grandes regiões; de modo geral, essa porção contém entre 60 e 90\% de ingressantes de escola pública e baixa renda. Vale mencionar que, ao contrário do critério étnico-racial, a medida de renda familiar é menos discriminante das instituições em âmbito regional.

\section{FIGURA 2}

(A) DISTRIBUIÇÃO PERCENTUAL DE INGRESSANTES DE ESCOLA PÚBLICA E BAIXA RENDA, POR INSTITUIÇÃO, E (B) DIFERENÇA ENTRE ESSE PERCENTUAL NUM AGRUPAMENTO DAS 104 IFES - BRASIL - 2012/2016

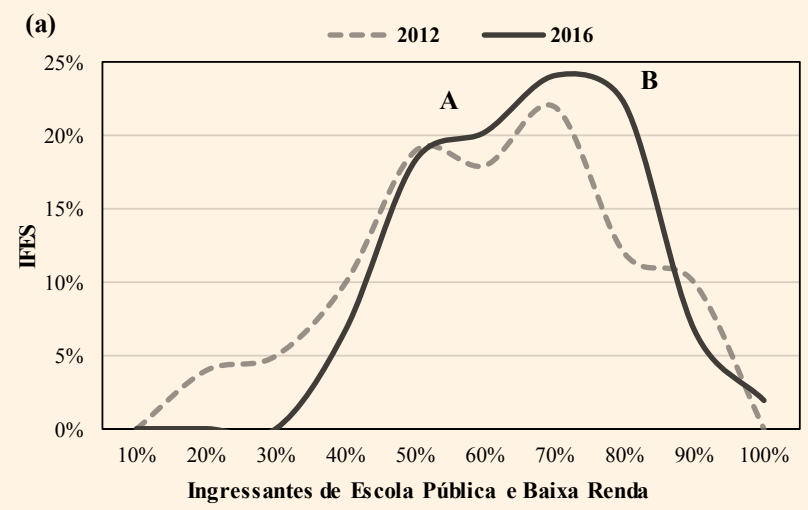

(b)

Fonte: Elaboração própria com base em dados do CES 2012/2016 e Enem 2011/2015 (Inep).

Pela Figura 2b, lê-se que somente sete Ifes não atendiam, em 2012, o mínimo de $25 \%$ de ingressantes provenientes de escola pública e de famílias com rendimentos mensais per capita inferiores a 1,5 salário-mínimo. Quatro anos depois, todas elas passaram a atingir pelo menos um terço de estudantes nessa condição. 
Apenas para fim de exemplificação, os menores resultados alcançados foram os da UnB, que saiu de 21,1 para $33,4 \%$ no período analisado, aumento equivalente a 12,3 p.p. Em contraste, as maiores variações absolutas encontradas foram na já citada Unifei, cujo percentual de estudantes de escola pública e baixa renda cresceu 26,3 p.p., partindo de 17,1\% em 2012 para 43,4\% em 2016.

Finalmente, é preciso destacar que das 97 Ifes que já cumpriam os requisitos previstos em lei, quase dois terços delas observaram crescimento no percentual de estudantes oriundos de escola pública e de famílias de baixa renda. Em algumas instituições, esses valores chegaram a patamares bastante elevados, como nos casos do Instituto Federal do Acre (Ifac) e do Instituto Federal Baiano (IF Baiano), em que se superou a marca de $90 \%$ de estudantes dessa condição. Por outro lado, determinadas instituições observaram decréscimos substancias em seus respectivos percentuais, como a Unifap (de 71,4\% em 2012 para 51,8\% em 2016), o Ines (de 87,5 para 62,5\%) e a Universidade Federal da Integração Latino-Americana (Unila, de 80,9 para 48,9\%). De toda sorte, importa notar que, em todos os casos, o percentual de estudantes de escola pública e de baixa renda supera, em muito, a marca de $25 \%$ prevista em lei.

Ainda sobre a problemática já discutida, é visível que, particularmente para os critérios de procedência escolar e renda familiar per capita, certo número de Ifes, usualmente aquelas mais inclusivas no ano de 2012, foram seriamente penalizadas após a implantação da Lei de Cotas. Suspeitamos que há duas razões de fundo para explicar tais reduções. Primeiramente, é bem possível que, por ter sustado as políticas de ação afirmativa já empregadas por muitas Ifes até 2012, os critérios para delimitação dos beneficiários da Lei de Cotas possam ter sido menos inclusivos e/ou menos abrangentes que aqueles já adotados no âmbito das próprias instituições - verificar essa hipótese, contudo, implica um olhar atencioso a cada caso, tarefa que vai além do escopo deste artigo. Por ora, identificamos poucos estudos que tenham executado análises similares em instituições específicas, confirmando ou não as preocupações aqui sistematizadas (e.g. TRESOLDI et al., 2015; NOGUEIRA et al., 2017).

Em segundo lugar, reforçamos a preocupação de Campos, Feres Júnior e Daflon $(2014$, p. 6) a respeito de possíveis vieses na implantação da Lei de Cotas via Sistema de Seleção Unificada (Sisu). Na medida em que a política cria contingentes exclusivos de candidatos às modalidades de cotas em função da combinação dos critérios adotados, e delimita a concorrência especificamente entre os cotistas que se candidataram a uma vaga por uma determinada modalidade, incorre-se no risco de preencher vagas reservadas às cotas com candidatos que apresentaram desempenho superior ao de não cotistas. Imaginando uma situação hipotética na vigência dessa regra: caso todos os candidatos oriundos do ensino médio público concorram pelas vagas reservadas a egressos da rede pública, um determinado curso terá, no máximo, metade dos ingressantes dessa procedência escolar; na prática, isso significa que a Lei de Cotas deixaria de ser um piso para a inclusão social e passaria a ser um teto. Na mesma linha, os autores supracitados observaram que, em 11\% dos cursos disponibilizados no Sisu 2014/1º semestre, 
a nota de corte dos cotistas foi mais elevada do que a da ampla concorrência uma evidência de tal distorção. Ao que parece, algumas universidades notaram e corrigiram esses processos de "superseleção dos cotistas", a exemplo da UFMG (NOGUEIRA et al., 2017). Porém a ausência de uma normativa sobre essa questão em âmbito nacional pode deixar a correção de tais vieses ao sabor das deliberações dos conselhos universitários.

\section{CONSIDERAÇÕES FINAIS}

Neste texto, lançamos mão de análises descritivas a partir de cruzamentos entre duas importantes bases de dados nacionais - o Censo da Educação Superior e o Exame Nacional do Ensino Médio -, para permitir a composição de um retrato socioeconômico e racial do corpo discente de ingressantes dos cursos de graduação das Ifes, visando a contemplar três critérios de delimitação dos beneficiários da política de reserva de vagas subscrita na Lei n. 12.711/2012, também conhecida como Lei de Cotas. Nossos achados apontaram que, em linhas gerais, a participação de ingressantes oriundos do ensino médio público aumentou de 55,4 para 63,6\% entre 2012 e 2016, com substanciais acréscimos para estudantes pretos, pardos e indígenas. Esses incrementos aconteceram para a maioria absoluta das instituições, em particular para aquelas mais seletivas e que partiam de patamares de inclusão social mais baixos; por outro lado, algumas das Ifes parecem ter sido penalizadas pelas ações afirmativas e tornaram-se menos inclusivas que em 2012, embora ainda obedeçam aos requisitos mínimos da Lei.

Entre as limitações desta pesquisa, ressaltamos que, por se tratar de uma análise exploratória, não tivemos a pretensão de isolar o efeito da reserva de vagas das demais políticas que possam ter contribuído para a alteração do perfil discente das instituições, a exemplo da adoção gradual do Sisu, de transformações no perfil dos egressos do ensino médio e de medidas para a ampliação do acesso implantadas desde a última década. Também reforçamos que a composição das variáveis de análise obedeceu a escolhas adotadas pelos autores e que, evidentemente, são passíveis de rediscussão. Do mais, restam em aberto questões relevantes para a compreensão do alcance da Lei de Cotas na democratização das oportunidades de acesso ao ensino superior. Primeiro, é preciso investigar quem foram os principais beneficiários da reserva de vagas destinada à rede pública; existem indícios de que as cotas, por não diferenciarem as distintas categorias administrativas das escolas públicas de origem, possam estar beneficiando egressos de escolas técnicas estaduais e federais, as quais tradicionalmente realizam exames de admissão e atraem estudantes de maior nível socioeconômico (ver NOGUEIRA et al., 2017). Segundo, é necessário repensar o critério de reserva de vagas baseado na renda familiar mensal, pois, como visto, este tem sido pouco efetivo em alterar o perfil dos ingressantes por ser excessivamente abrangente. Terceiro, ainda não sabemos como os distintos cursos de graduação, marcados por uma forte estratificação horizontal em função da seletividade de ingresso e do retorno econômico após a conclusão, têm respondido à reserva de vagas e 
como um conjunto de critérios homogêneos para todos os beneficiários pode ter efeitos diferenciados a depender da área de conhecimento, concorrência, prestígio social, etc.

Por último, é preciso envidar esforços para compreender o impacto da reserva de vagas sobre o desempenho acadêmico dos estudantes. Vilela et al. (2017, p. 680-681) discorrem que a adoção das cotas não teria impactos significativos sobre a nota média dos aprovados porque existiriam candidatos elegíveis para as suas modalidades com desempenho elevado em número suficiente para preencher as vagas. Esse quadro se explica pelo diagnóstico de Andrade (2017) de que a maior parte da demanda efetiva pelo ensino superior, em particular aquela de menor qualificação acadêmica, é “retida” ao longo do ensino médio e pela sua própria participação e desempenho no Enem. Procurando entender essas conclusões à luz dos nossos achados, é possível inferir que, por mais que a reserva de vagas tenha diversificado o perfil dos ingressantes das Ifes, o corpo discente em nível superior ainda tem sido intensamente selecionado - se, por um lado, essa constatação nos assegura que as universidades têm avançado em equidade sem comprometer a excelência, por outro lado nos indica o quanto o sistema de ensino superior no Brasil deve avançar para tornar-se realmente inclusivo, cuja meta envolverá a qualificação dos egressos da educação básica.

Em que se pesem todas essas considerações, acreditamos que a maior contribuição deste estudo está em apresentar uma visão abrangente dos resultados da Lei de Cotas sobre o conjunto de Ifes no Brasil, por meio de uma abordagem inovadora que faz uso do cruzamento de bases de dados em âmbito individual. Ademais, nossos achados potencialmente subsidiam ulteriores investigações empíricas que possam clarificar questões ainda abertas acerca da implantação da Lei e, consequentemente, dos impactos do sistema de reserva de vagas sobre o perfil discente das instituições federais. Por ser uma análise exploratória, esperamos dar continuidade ao estudo procurando avançar sobre os seguintes passos: 1) manter atualizado o acompanhamento da política de cotas pelo monitoramento contínuo do perfil discente das Ifes, podendo-se aprimorar os procedimentos aqui apresentados; 2) realizar novos recortes analíticos investigando-se, por exemplo, as transformações no perfil discente por determinados cursos de graduação ou comparando cursos presenciais e a distância, ofertados no interior ou nas capitais; 3) construir cenários contrafatuais para simular alterações nos critérios de delimitação dos beneficiários da Lei de Cotas visando a subsidiar a revisão da legislação prevista para 2022.

Com isso, esperamos colaborar para a geração de insumos que supram parte da lacuna existente quanto ao monitoramento e à avaliação da Lei n. 12.711/2012. Um programa nacional de reserva de vagas de tamanha envergadura não pode passar despercebido e, em conjunto com análises específicas em âmbito institucional, necessita ser investigado com abrangência nacional e regional, com o intuito de subsidiar o acompanhamento da execução, dos resultados e dos impactos de tal legislação, bem como sua eventual reformulação visando a potencializar os objetivos esperados. 
ANDRADE, C. Y. Acesso ao ensino superior no Brasil: o impacto das ações afirmativas. In: CONGRESSO BRASILEIRO DE SOCIOLOGIA, 18., 2017, Brasília. Anais eletrônicos do $18^{\circ}$ Congresso Brasileiro de Sociologia. Brasília: UnB, 2017.

ARTES, A.; RICOLDI, A. M. Acesso de negros no ensino superior: o que mudou entre 2000 e 2010. Cadernos de Pesquisa, São Paulo, v. 45, n. 158, p. 858-881, 2015.

BRASIL. Congresso Nacional. Lei $n^{\circ} 12.711$, de 29 de agosto de 2012. Dispõe sobre o ingresso nas universidades federais e nas instituições federais de ensino técnico de nível médio e dá outras providências, Brasília, DF, 29 ago. 2012. Disponível em: http://www.planalto.gov.br/ccivil_03/_ato2011-2014/2012/lei/112711.htm. Acesso em: 10 out. 2017.

CARVALHAES, F.; FERES JÚNIOR, J.; DAFLON, V. T. 0 impacto da Lei de Cotas nos estados: um estudo preliminar. Rio de Janeiro: IESP/UERJ, 2013. 21 p. (Textos para Discussão GEMAA, n. 1).

CAMPOS, L. A.; FERES JÚNIOR, J.; DAFLON, V. T. O desempenho dos cotistas no Enem: comparando as notas de corte do Sisu. Rio de Janeiro: IESP/UERJ, 2014. 23 p. (Textos para Discussão GEMAA, n. 4).

CORBUCCI, P. R. Evolução do acesso de jovens à educação superior no Brasil. Brasília: Ipea, 2014. 33 p. (Texto para Discussão n. 1950).

DAFLON, V. T.; FERES JÚNIOR, J.; CAMPOS, L. A. Ações afirmativas raciais no ensino superior público brasileiro: um panorama analítico. Cadernos de Pesquisa, São Paulo, v. 43, n. 148, p. 302-327, 2013.

GUIMARÃES, A. S. A. As cotas nas universidades públicas 20 anos depois. In: ARTES, A.; UNBEHAUM, S.; SILVÉRIO, V. (org.). Ações afirmativas no Brasil: reflexões e desafios para a pós-graduação. São Paulo: Cortez/Fundação Carlos Chagas, 2016. p. 93-124.

IKUTA, C. Y. S. Sobre o Conceito Preliminar de Curso: concepção, aplicação e mudanças metodológicas. Estudos de Avaliação Educacional, São Paulo, v. 27, n. 66, p. 938-969, 2016.

INSTITUTO NACIONAL DE ESTUDOS E PESQUISAS EDUCACIONAIS ANÍSIO TEIXEIRA. Relatório do $1^{\circ}$ ciclo de monitoramento das metas do PNE: biênio 2014-2016. Brasília: Inep, 2016. 590 p. Disponível em: http://portal. inep.gov.br/web/guest/publicacoes. Acesso em: 27 dez. 2017.

JACCOUD, L.; THEODORO, M. Raça e educação: os limites das políticas universalistas. In: SANTOS, S. A. (org.). Ações afirmativas e combate ao racismo nas Américas. Brasília: MEC/Secad, 2005. p. 103-119.

LAZARO, A. Observatório da Lei de Cotas: proposta de avaliação da Lei n. 12.711/2012. In: ARTES, A.; UNBEHAUM, S.; SILVÉRIO, V. (org.). Ações afirmativas no Brasil: reflexões e desafios para a pós-graduação. São Paulo: Cortez/Fundação Carlos Chagas, 2016. p. 125-156.

NEVES, C. E. B.; MARTINS, C. B. Ensino superior no Brasil: uma visão abrangente. In: DWYER, T.; ZEN, E. L.; WELLER, W.; SHUGUANG, J.; KAIYUAN, G. (org.). Jovens universitários em um mundo em transformação: uma pesquisa sino-brasileira. Brasília: Ipea; Pequim: SSAP, 2016. p. 95-124.

NEVES, C. E. B.; RAIZER, L.; FACHINETTO, R. F. Acesso, expansão e equidade na educação superior: novos desafios para a política educacional brasileira. Sociologias, Porto Alegre, v. 9, n. 17, p. 124-157, 2007.

NOGUEIRA, C. M. M.; NONATO, B. F.; RIBEIRO, G. M.; FLONTINO, S. R. D. Promessas e limites: o Sisu e sua implementação na Universidade Federal de Minas Gerais. Educação em Revista, Belo Horizonte, n. 33, p. 1-31, 2017.

RABELO, R. P. Desigualdades sociais no ensino superior: explorando tendências e impactos da Lei de Cotas. In: REUNIÃO NACIONAL DA ANPED, 38., 2017, São Luís. Anais eletrônicos da $38^{a}$ Reunião Nacional da ANPED. São Luís: UFMA, 2017.

RIBEIRO, C. A. C.; SCHLEGEL, R. Estratificação horizontal da Educação Superior no Brasil (1960 a 2010). In: ARRETCHE, M. (org.). Trajetórias das Desigualdades: como o Brasil mudou nos últimos cinquenta anos. São Paulo: Editora Unesp/CEM, 2015. p. 133-162.

SENKEVICS, A. S.; MACHADO, T. S.; OLIVEIRA, A. S. A cor ou raça nas estatísticas educacionais: uma análise dos instrumentos de pesquisa do Inep. Brasília: Inep, 2016. 48 p. (Texto para Discussão $\mathrm{n}^{\circ} 41$ ). 
SENKEVICS, A. S. Contra o silêncio racial nos dados universitários: desafios e propostas acerca da Lei de Cotas. Educação e Pesquisa, São Paulo, v. 44, p. 1-23, 2018. Disponível em: http://www.scielo.br/scielo. php?script=sci_arttext\&pid=S1517-97022018000100317\&lng=pt\&nrm=iso\&tlng=pt.

SIMÕES, A. A. As metas de universalização da Educação Básica no Plano Nacional de Educação: o desafio do acesso e a evasão dos jovens de famílias de baixa renda no Brasil. Brasília: Inep, 2016. 46 p. (PNE em Movimento n. 4).

SINGER, J. D.; WILLETT, J. B. Applied longitudinal data analysis: modeling change and event occurrence. New York: Oxford University Press, 2003.

TRESOLDI, T.; SIMÕES, L. J.; NABARRO, E.; POLIDORI, M. M. Análise de desempenho acadêmico de estudantes com ingresso por reserva de vagas na Universidade Federal do Rio Grande do Sul (UFRGS). In: SIMPÓSIO DE AVALIAÇÃO DA EDUCAÇÃO SUPERIOR, 1., 2015. Anais AVALIES 2015. Porto Alegre: UFRGS, 2015.

VERHINE, R. E.; DANTAS, L. M. V. A avaliação do desempenho de alunos de educação superior: uma análise a partir da experiência do Enade. In: LORDÊLO, J. A. C.; DAZZANI, M. V. (org.). Avaliação educacional: desatando e reatando nós. Salvador: Edufba, 2009. p. 173-199.

VILELA, L.; TACHIBANA, T. Y.; MENEZES FILHO, N.; KOMATSU, B. As cotas nas universidades públicas diminuem a qualidade dos ingressantes? Estudos em Avaliação Educacional, São Paulo, v. 28, n. 69, p. 652-684, set./dez. 2017.

NOTA: Os autores tiveram igual contribuição em todas as etapas de produção deste estudo.

\section{COMO CITAR ESTE ARTIGO}

SENKEVICS, Adriano Souza; MELLO, Ursula Mattioli. O perfil discente das universidades federais mudou pós-lei de cotas?. Cadernos de Pesquisa, São Paulo, v. 49, n. 172, p. 184-208, abr./jun. 2019. https://doi.org/10.1590/198053145980 
